\title{
Cost Benefit Analysis of a Fire Safety System Based on the Life Quality Index
}

\author{
MICHAEL HASOFER and IAN THOMAS \\ Centre for Environmental Safety and Risk Engineering (CESARE) \\ Victoria University \\ PO Box 14428 \\ Melbourne 8001 \\ Australia
}

\begin{abstract}
Carrying out a cost benefit analysis requires, on the one hand, estimation of costs for the installation, running and maintenance of the system under consideration. On the other hand, it also requires estimation of the net reduction (in dollars) in property damage, as well as the effect on occupant injuries and fatalities.

Costing of injuries does not raise ethical problems, but there is no universally accepted answer to the question "What is the value of human life?" Beever and Britton carried out a cost benefit analysis of various fire safety measures in one and two family dwellings in Australia but carried out analysis of the financial aspects separately from consideration of life safety. Thus it was not possible to uniquely rank the various options considered.

In this paper their analysis is updated by integrating the financial aspects with the life safety aspects using a new approach, called the Life Quality Index (LQI) method, that has been developed by the Institute for Risk Research of the University of Waterloo, Canada. The life quality index can be calculated for many countries from widely available and reliable statistical data. It has been successfully used in environmental science and nuclear and structural engineering.

When applied, as an example of the use of the method, to a cost benefit analysis of the use of sprinklers in one and two family dwellings in Australia using the Beever and Britton data, the LQI methodology yields a financial measure of the benefit expected if sprinklers were installed in one and two family dwellings. The analysis shows a very low benefit to cost ratio and it is thus concluded that installation of sprinklers in these dwellings is not cost effective.
\end{abstract}

KEYWORDS: risk assessment, cost benefit, sprinklers, apartment fires, life quality index

\section{NOMENCLATURE LISTING}

$\begin{array}{llll}e & \text { Average life expectancy } & N & \text { Population size } \\ e_{x} & \text { Life expectancy at age } x & q & \text { Mortality rate } \\ f_{x} & \text { Distribution of population age } & q_{x} & \text { Age-specific mortality rate } \\ k(x) & \text { Age dependent factor } & r & \text { Interest rate } \\ l_{x} & \text { Number of persons at age } x & w & \begin{array}{l}\text { Fraction of time spent working } \\ \text { to produce income }\end{array} \\ L_{x} & \begin{array}{l}\text { Number of person years in age } \\ \text { interval }(x, x+1)\end{array} & & \\ n & \text { Useful life of equipment (years) } & x & \begin{array}{l}\text { subscript } \\ \text { Age (years) }\end{array}\end{array}$

\section{INTRODUCTION}

Cost benefit analyses require, on the one hand, costs for the installation, running and maintenance of the system under consideration and, on the other hand, estimates of the value of the net reduction in property damage, injuries and fatalities. Costing of injuries does not raise ethical problems but there is no universally accepted answer to the question "What is the value of a life?" When Beever and Britton [1] examined the cost effectiveness of fire safety measures (including sprinklers) in one and two family dwellings in Australia, they carried out an analysis of the financial aspects separately from their consideration of lives saved, thus avoiding the ethical dilemma. However, in this situation it is not possible 
to uniquely rank the options for fire safety system components since there is no global measure of net benefit.

In this paper, their analysis for sprinklers will be updated by integrating the financial aspects with the lifesaving aspects using a relatively new approach, called the Life Quality Index (LQI) method, that has been developed by the Institute for Risk Research of the University of Waterloo, Canada [2, 3]. The life quality index can be calculated for many countries from widely available and reliable statistical data and it has been successfully used in many studies in environmental science and structural and nuclear engineering.

Beever and Britton based their analyses on data from approximately 32,000 Australian one and two family dwelling fires between 1989 and 1994 along with similar statistics from the USA. They examined the cost effectiveness of various fire safety measures for reducing occupant fatalities, injuries and property loss. For domestic sprinklers to AS 2118.5 they estimated that the cost (installation and maintenance) was \$30-60 million per life saved.

In the design process the choice of the components used in a fire safety system should be based on a cost benefit analysis. Thus it is necessary to obtain or estimate costs for the installation, running and maintenance of the system under consideration and the property damage due to fire. It will also be necessary to consider, along with the property damage, the damage to life in terms of injuries and fatalities.

The LQI methodology does this and in this paper will thus yield a global measure of the benefit that can be expected from installing sprinklers in one and two family dwellings based on the data used previously by Beever and Britton. The primary purpose of the paper is to present a new methodological tool that has not so far been used in fire engineering and to illustrate its use with a case study. It is hoped that this paper will spur other researchers to carry out further case studies of this new methodology in order to assess its potential in the field of cost benefit analyses for fire engineering.

\section{TREATMENT OF FATALITIES}

As pointed out by Ramachandran [4], costing of the danger to life in terms of injuries does not raise ethical problems: insurance claims provide some valuation; an alternative method is to aggregate various components - treatment costs, the value of time lost, social cost and the value of pain and suffering. On the other hand, there is no generally accepted answer to the question "What is the value of a human life?" Indeed, many people would assert that human life has infinite value. Ramachandran [4] has listed a number of possible methods of valuing human life but none of these have been generally accepted by the engineering community. In fact, in the third edition of the SFPE Handbook of Fire Protection Engineering, the chapter that appeared in the second edition that was devoted to the value of human life was abandoned and replaced by a more general chapter entitled "Measuring Fire Consequences in Economic Terms". (See Ramachandran and Hall [5]). It is notable that all the references to the valuation of human life in the third (2002) edition are earlier than 1986.

The manner in which life quality index method addresses the issue of the value of human life is briefly described below. For a full description of the method see Nathwani et al [2] and the more recent paper by Pandey and Nathwani [3].

The quality of life, or total enjoyment of life, may be thought of as having two dimensions: intensity and duration. The value, utility or enjoyment derived from wealth production is the intensity. The duration refers to the (leisure or discretionary) time available to a person outside the occupational activities that produce wealth. The important idea is that intensity and duration are exchangeable. A person may freely substitute one for the other over a lifetime to optimise the total enjoyment of life. That is, we expend a part of our lives working in order to create the "wealth" required for "comfort and enjoyment". We then expend a part of that wealth to extend our expectation of life in good health. This idea is similar to the so-called "hedonic wage methodology" according to which "workers are willing to accept additional risks of death in the workplace if they can obtain a monetary compensation affording them the same expected utility level" (Thaler and Rosen [6]).

The Life Quality Index can be considered to be a social indicator derived to reflect the expected length of "good" life, in particular the enhancement of the quality of life by extended good health and enjoyment.

The Life Quality Index (LQI) is derived from two aggregated indicators: 
- life expectancy at birth

- real domestic product per person

The life quality index can also be viewed as an individual utility function. People's choices reveal their preferences. Presumably, people on average work just enough so that the marginal value of the wealth produced (or income earned) is, in their judgment, equal to the marginal value of the time they "lose" while at work.

The life quality index can be calculated for many countries from widely available and reliable statistical data. It can be used in the context of cost benefit analyses as a yardstick to judge if a policy or an undertaking is of net benefit to society.

\section{BASIC DATA}

The basic data related to the cost and benefit aspects of sprinkler installation in one and two families' dwellings are taken from the published work of Beever and Britton [1]. Page references are given in brackets.

The data were compiled for Australia for the year 1999. Monetary values are expressed in 1999 Australian dollars.

- average number of persons per household (p.73) 2.99

- rate of fire incidents (p.73) 0.626 fires per 1000 persons per year

- fatality rate without sprinklers (p.74) 7 per 1000 fires

- fatality rate with sprinklers (p.74) in the range 1.46 to 3.89 per 1000 fires

- injury rate (p.75) 15-30 per 1000 fires, either unaffected or perhaps increased by sprinklers

- cost per injury (p.75) \$21,100 in Victoria, Australia, including hospital costs, pain and suffering and value of average lost work time

- property losses without sprinklers (p.77) $\$ 24,000$ per fire

- $\quad$ property losses with sprinklers (p.77) \$3,900 per fire

- initial cost of sprinkler installation (p.78, etc) in the range of $\$ 1500$ to $\$ 3300$

- annual maintenance cost (p.78, etc) in the range of $\$ 400$ to $\$ 500$

The nominal interest rate $r$ will be taken as 5\% per year and the useful life of the sprinkler system will be taken as 20 years.

Details of the evaluation of data from [1] are given in Appendix 2.

It must be remembered that the data given above refer to Australian conditions. For example, sprinkler systems are installed in accordance with Australian Standard AS 2118.5 which requires yearly maintenance of the system in accordance with the requirements of AS 1851.3. On the other hand, Butry et al [7] do not estimate maintenance, repair and replacement costs of the sprinkler system on the grounds that in the USA the sprinkler system is integrated with the regular cold-water plumbing inside the house and has therefore no separable maintenance needs. This assumption is very beneficial in support of sprinklers but seems unreasonable when compared with maintenance costs even for domestic smoke alarms which are much simpler and less costly but at a minimum require annual battery replacement.

\section{THE QUALITY OF LIFE FORMULA}

\section{General principles}

1. The Kaldor-Hicks Compensation Principle: A policy is to be judged socially beneficial if the gainers receive enough benefits that they can compensate the losers fully and still have some net gain left over. It will be assumed that governments will act in accordance with that principle, 
which will ensure that societal income distribution will not affect the value of the quality of life index. [3]

2. The life measure principle: The measure of health and safety benefit is the increase in expected life in good health.

\section{The model}

The model determines an acceptable level of expenditure that can be justifiably incurred in exchange for a reduction in the risk of death that results in improved life quality for all. This value can be considered as the Societal Willingness to Pay (SWTP). It relies on two major indicators: life expectancy as a measure of safety, and the real gross domestic product per person (GDP) as a measure of the quality of life. Both indicators have been in use for half a century to express the wealth and health of a nation in numbers, and they are reliably measured.

The SWTP for a small reduction in risk can be formulated as a problem of decision making under uncertainty, and then well-established principles of utility theory can be applied to derive a Life Quality Index at the societal level.

\section{Life expectancy for individuals}

Life tables are available from government sources. Usually the data are provided at one year intervals and the calculations are carried out over a fixed starting number of individuals, called a cohort, usually 100,000. The data are usually provided for each age. For age $x$ the following quantities are given:

$$
\begin{aligned}
& q_{x}=\text { proportion dying between ages } x \text { and } x+1 \text { (the age-specific mortality rate) } \\
& l_{x}=\text { number of persons at exact age } x \\
& L_{x}=\text { number of persons-years lived within the age interval } x \text { to } x+1 \\
& e_{x}=\text { expectation of life at exact age } x \text { (the age-specific life expectancy) }
\end{aligned}
$$

Knowledge of $q_{x}$ for the range of $x$, (usually 0-100) allows the calculation of the three other quantities. The formulae are given in Appendix 1.

\section{Life expectancy at the societal level}

Life expectancy at the societal level $e$ is an aggregate of the values for all individuals in society. To achieve this, the expectation of life $e_{x}$ must be averaged over the distribution of population age $f_{x}$ according to the formula

$$
e=\sum_{x} e_{x} f_{x}
$$

\section{Estimation of a change in life expectancy}

The change in life expectancy brought out by a change in conditions, whether for the better or the worse, can be measured by means of an age-dependent factor $k(x)$ that defines the modified age-specific mortality rate $q_{x}^{*}$ by the equation $q_{x}^{*}=k(x) q_{x}$. The modified life expectancy at the societal level $e^{*}$ can then be estimated, using the formulae given in Appendix 1, by following the following procedure:

1. use the recurrence equation $l_{x+1}^{*}=l_{x}^{*}\left(1-q_{x}^{*}\right)$ to evaluate the new age distribution $l_{x}^{*}, \quad x=1, \ldots$

2. use the equation

$$
L_{x}^{*}=\frac{l_{x}^{*}+l_{x+1}^{*}}{2}
$$


3. find the modified life expectancy at age $x$

$$
e_{x}^{*}=\frac{\sum_{i \geq x} L_{i}^{*}}{l_{x}^{*}}
$$

4. use the equation

$$
e^{*}=\sum_{x} e_{x}^{*} f_{x}
$$

to find the modified life expectancy at the societal level.

Finally, the change in life expectancy de is given by $e^{*}-e$.

However, experience suggests that age-specific increases in mortality rates are sometimes not readily available. So an overall increase in crude mortality rate, $d q$, has been often used to express the impact of increased risk. In this case, a simplified formulation can be derived for estimating de, without going through an elaborate life table analysis. It turns out that for a small change $d q$ in mortality rate (less than $0.01 \%$ ), the relative change in life expectancy de/e is approximately proportional to $d q$. (Nathwany et al [3] p.66). For the 1992 Canadian Life Table, a close approximation is given by $d e / e=19.2 d q$, while for the 1985 US Life Table a close approximation was found to be $d e / e=20.61 \mathrm{dq}$.

Using the Australian Bureau of Statistics Life Tables [8], the approximation for Australian conditions was found to be

$$
d e / e=20 d q .
$$

\section{The Quality of Life criterion}

Let $w$ denote the fraction of time spent working to produce income that supports consumption. We shall call 1-w the fraction of leisure time, which will therefore include sleep time. Let now

$$
K=\frac{w}{(1-w)}
$$

Then $K$ is the ratio of the average work time to the average leisure time.

Furthermore, let $e$ be the societal life expectancy, and let $g$ be the gross domestic product (GDP) per capita. This is roughly the sum of all incomes created by labour and capital (i.e. stored labour) per capita per year. It is what creates the possibilities to "buy" additional life years through better medical care and improved safety.

Both $g$ and $e$ vary considerably with time and from country to country. In applications, it is therefore necessary to use recent national statistics. It is also necessary to make adjustments for inflation and for interest rates. On the other hand, social indicators compiled by the OECD (see OECD [7]) indicate that the parameter $w$ (the fraction of time spent to produce income that supports consumption) appears to vary little in comparison with $g$ and $e$.

Lind et al [8] have estimated $w$ in North America by the following reasoning: the "average person" works about 50 years out of 80 years of life, 48 weeks out of 52, and about 42 hours per week (including time spent traveling to and from work) out of 168 . Work thus consumes roughly the proportion $w=(50 / 80) \times$ $(48 / 52) \times(42 / 168) \times 100=14.4 \%$.

In OECD countries and countries with similar standards of living, $w$ can be taken to be approximately $1 / 8=$ $12.5 \%$, so that $K=1 / 7$. 
Let now $t=(1-w) e$ be the leisure time available to a person. The basic idea of the Life Quality Index $L$ is that duration (available time) and intensity (wealth) are freely exchangeable. The following model is believed to be a fair and reasonable representation of the aggregate value received by individuals: any product of the form $L=f(g) h(t)$, where the factor $f(g)$ represents the intensity of enjoyment per unit time while the factor $h(t)$ represents the duration of the available leisure time. It can then be shown (Nathwani et al [4], Pandey and Nathwani [5]) that with a few weak additional assumptions the formula for the life quality index $L$ can be taken as

$$
L=g^{K} e
$$

The general acceptance criterion for (relatively small) expenditure into safety projects resulting in life saving will then be:

$$
d L=\frac{\partial L}{\partial g} d g+\frac{\partial L}{\partial e} d e \geq 0
$$

The criterion can be written as

$$
K \frac{d g}{g}+\frac{d e}{e} \geq 0 .
$$

More practically it can be written in the form

$$
(-d g) \leq \frac{g}{K} \frac{d e}{e}
$$

The term (-dg) (a positive quantity) represents the cost of the safety project. If the safety project also results in a per capita reduction of financial loss $d g^{*}$ (a negative quantity), then the criterion becomes

$$
(-d g)+d g^{*} \leq \frac{g}{K} \frac{d e}{e}
$$

The benefit to cost ratio (greater than one for a desirable project) is given by

$$
\frac{(d e / e)}{K(d g / g)} \text {. }
$$

Suppose the benefits of the proposed measure are received by a population of size $N$. The social willingness to pay, SWTP, can be obtained at societal level from the formula

$$
\mathrm{SWTP}=d g \times N=N \frac{g}{K} \frac{d e}{e} \$ / \text { year. }
$$

Some hold that the change of expected (monetary) lifetime income is a measure that society is more interested in than the societal life expectancy and the GDP separately. Actually, since $g$ is the gross 
domestic product per capita and $e$ is the societal life expectancy, $G=g e$ is precisely the expected (monetary) lifetime income per capita. So the change of that lifetime income due to small changes $d g$ and $d e$ in $g$ and $e$ will be given by $d G=g d e+e d g$. So the change $d G$ can be evaluated for every safety project studied.

\section{RECENT WORK USING THE LQI}

The life quality index has been successfully used in many case studies. Nathwani et al [2] have used it to analyze:

1. the effectiveness of a large number of US federal health and safety regulation standards, including the US benzene standard and regulations to control releases of dioxin

2. risks and costs associated with electricity generating options

3. radiation exposure

4. compensation for hazardous occupations

5. allocation of health care resources

6. cigarette smoking

7. marketing of a hazardous product

8. hazardous waste disposal, including nuclear fuel waste disposal

In addition, Voortman et al [11] have used the Life Quality Index to develop a methodology for defining acceptable flooding risk in the Netherlands. Rackwitz [12] has used the Life Quality Index to assess different reconstruction policies for a dam that was destroyed by an earthquake.

In the last four years more than fifteen refereed papers expounding various aspects of the LQI index have been published in engineering journals and conference proceedings. In addition, a number of authors have described applications of the LQI methodology to various cost benefit problems such as:

(a) the Canadian Particulate Matter and Ozone standard [13]

(b) policy responses to the risk of air pollution [14]

(c) nuclear safety programs [15]

In paper [15], Pandey and Nathwany compared the results of the LQI model with empirical estimates of the "value of statistical life" (VSL) utilized by the Royal Society of Canada in the context of air pollution control options in 1996. The estimates obtained varied over a range of \$2-10 million (Canadian) and the age-adjusted central estimate finally adopted was $\$ 4.1$ million. Corresponding to the VSL is, in the LQI context, the "social willingness to pay" (SWTP). It was estimated as $\$ 4.4$ million. The fact that the VSL estimates are in line with the SWTP derived from the LQI model provides an empirical validation of the LQI approach.

The most recent previous publication on cost-benefit analysis of residential fire sprinkler systems is Butry et al 2007 [7] They take into account the value of a statistical life but devote just nine lines to justify the figure they use, noting that "this report provides background on recent research on the value of life, without suggesting that it is the only, or most appropriate value". The "recent research" alluded to is Viscusi and Aldy [16] whose approach is based on the "hedonic wage methodology" (Thaler and Rosen [6]). But Viscusy and Aldy are primarily interested in actual market estimates as derived from econometric analyses of labour markets, while the LQI is a tool for the assessment of risk reduction initiatives based on the principles of rational decision analysis. 


\section{THE COST-BENEFIT CALCULATION FOR SPRINKLERS IN 1-2 FAMILY DWELLINGS}

Having decided on a useful life of the sprinkler system of 20 years and a nominal interest rate of $5 \%$, it is first necessary to evaluate the yearly cost of amortization of the sprinkler installation cost, using the amortization formula

$$
B=A r \frac{(1+r)^{n}}{(1+r)^{n+1}-1}
$$

Where $A=$ Initial cost

$B=$ Yearly repayment

$n=$ Useful life of equipment in years.

The range of the amortization cost of a sprinkler system is therefore \$111 to \$245 per year per household.

Adding the annual maintenance cost ( $\$ 400$ to $\$ 500$ ) the total cost per household is $\$ 511$ to $\$ 745$.

Since there are 2.99 persons per household on average, the total cost per person is in the range $\$ 171$ to $\$ 249$ per year.

The range of fatality reductions per 1000 fires is given by (7-3.89) to (7-1.46) , i.e.3.11 to 5.54 per 1000 fires. One could easily imagine a model of age-dependent mortality reduction achieved through sprinklers, although the authors are not aware of published data on the topic. However, for simplicity, it will be assumed in this paper that the mortality reduction is not age dependent. Since the rate of fire incidents is 0.626 fires per 1000 persons per year, it follows that the decrease in yearly fatality rate per person $d q$ is

$$
d q=\frac{(3.11 \text { to } 5.54) \times 0.626}{1000 \times 1000}=(1.9 \text { to } 3.5) \times 10^{-6}
$$

So $\quad \frac{d e}{e}=20 d q=(38.9$ to 69.4$) \times 10^{-6}$

The decrease in property losses per person per year due to sprinklers was

$$
\frac{(24000-3900) \times 0.626}{1000}=\$ 12.60
$$

The Australian GDP per capita per year in 1999 was \$39,758 according to the Reserve Bank of Australia (Bulletin G10: Gross Domestic Product). Therefore

$$
d g=(\$ 171 \text { to } \$ 249)-\$ 12.6=\$ 158.4 \text { to } \$ 236.4
$$

and

$$
K \frac{d g}{g}=\frac{1}{7} \cdot \frac{(158.4 \text { to } 236.4)}{39758}=(569 \text { to } 849) \times 10^{-6}
$$

Finally the benefit to cost ratio, obtained from equation (11), is in the range 


$$
\frac{38.9}{849}=0.046 \text { to } \frac{69.4}{569}=0.122
$$

Clearly, the analysis shows that there is no serious cost-benefit oriented case to be made for introducing sprinklers in 1-2 family dwellings in Australia.

\section{DISCUSSION}

To assess the significance of the above benefit to cost ratio it is interesting to compare it to the results of an analysis carried out by Nathwany et al [2] p.90, where they apply the LQI methodology to 33 US Government regulations described by Viscusi [17]. The benefit to cost ratios they obtained varied from 20.2 to 0.0002 . However, 12 out of the 33 had a benefit to cost ratio greater than one. The introduction of passive restraint/seat belts in 1984 had a ratio of 7.5 and was therefore clearly cost effective. The top estimate of the sprinkler benefit to cost ratio, 0.122, ranked 18th. However, it should be noted that it had a much higher benefit to cost ratio than the regulation of exposure to asbestos in the USA in 1986, whose benefit to cost ratio was 0.03 ! This appears to indicate that the social choice of safety measures is not always entirely governed by rational economic considerations. In some cases emotional factors may well play an important role in the decision to implement the measure.

\section{APPENDIX 1}

As mentioned above, knowledge of $q_{x}$ for the range of $x$ allows the calculation of the three other quantities. The formulae to achieve this are as follows:

$$
l_{x+1}=l_{x}\left(1-q_{x}\right)
$$

Assuming linearity of deaths,

$$
L_{x}=\frac{\left(l_{x}+l_{x+1}\right)}{2} \text {, }
$$

and finally

$$
\begin{aligned}
e_{x} & =\frac{\text { total number of years lived by survivors at age } x}{\text { number of survivors aged } x} \\
& =\frac{\sum_{i \geq x} L_{x}}{l_{x}} .
\end{aligned}
$$

\section{APPENDIX 2}

\section{Initial cost of a domestic sprinkler installation and annual maintenance cost as per AS 2118.5}

Australian costs based on designs meeting AS 2118.5 were supplied by Australian construction cost consultants Rider Hunt. It is assumed that installation, testing and maintenance is undertaken by qualified tradesmen and that maintenance is in accordance with the requirements of AS 1851.3.

Four scenarios are considered:

1. A production built new house. 
2. A custom built new house.

3. An existing house

4. A medium density housing estate

For a production house of $150 \mathrm{~m}^{2}$ internal floor area:

The total installation costs for a sprinkler system have been calculated at A \$2,250. This is based on eight sprinkler heads. Piping would comprise of "Firelite" galvanised light wall tubing and fittings with a maximum $32 \mathrm{~mm}$ main sprinkler supply and $20 \mathrm{~mm}$ supply to sprinkler heads. Pipework is installed within roof space installation and does not require an installation within or under concrete slabs. It is assumed that mains water pressure is great enough so as not to require auxiliary pumps. Annual maintenance costs are assumed at being $A \$ 500$, based on quarterly level 2 routine maintenance (A $\$ 280)$, annual level 3 routine maintenance (A $\$ 175)$ and an annual material cost of $\mathrm{A} \$ 45$.

For a custom built house of $210 \mathrm{~m}^{2}$ internal floor area:

The total installation costs for a sprinkler system have been calculated at A\$3,300. This is based on ten sprinkler heads. Piping would comprise of "Firelite" galvanised light wall tubing and fittings with a maximum $32 \mathrm{~mm}$ main sprinkler supply and $20 \mathrm{~mm}$ supply to sprinkler heads. Pipework is installed within roof space installation and does not require an installation within or under concrete slabs. It is assumed that mains water pressure is great enough so as not to require auxiliary pumps.

As in the previous scenario, annual maintenance costs are assumed at being $\mathrm{A} \$ 500$.

For an existing house of $150 \mathrm{~m}^{2}$ internal floor area:

The total installation costs for a sprinkler system have been calculated at A\$3,300. This is based on eight sprinkler heads. Piping would comprise of "Firelite" galvanised light wall tubing and fittings with a maximum $32 \mathrm{~mm}$ main sprinkler supply and $20 \mathrm{~mm}$ supply to sprinkler heads. Pipework is installed within roof space installation and does not require an installation within or under concrete slabs. It is assumed that mains water pressure is great enough so as not to require auxiliary pumps.

As in the previous scenarios, annual maintenance costs are assumed at being A\$500

For a medium density housing estate of 5000 household it is assumed that through competition and economies of scale the installation costs could be reduced to $A \$ 1,500$ per household and that annual maintenance costs could be reduced through competition by $20 \%$ to $\mathrm{A} \$ 400$.

\section{Nominal interest and useful life}

An interest rate of $5 \%$ is the standard rate currently used in cost benefit analysis in Australia. Beever and Britton [1] have used a 20 year useful life for sprinklers. Butry et al [7] have used an interest rate of $4.8 \%$ and a useful life of 30 years.

Recalculating equations (13) to (18) using a useful life $n=30$ only increases the largest value of benefit to cost ratio from 0.122 to 0.127 , and this does not affect the conclusion of the paper. This is because maintenance costs (based on Australian standard AS 2118.5 requirements) constitute more than $50 \%$ of the total annual cost.

\section{Injury rates and costs}

Injury costs were ignored in the analysis of this paper for the following reasons:

1. It is not clear that sprinklers significantly reduce the number of civilian injuries. For example, according to the NFIRS 1995 data base, the civilian injury rate for sprinklered fires in the US was 55 injuries per 1000 fires, as compared with 47 for fires without sprinklers.

2. Estimated Australian injury costs are far lower than US costs ( e.g. A $\$ 21,100$ according to [1] against US\$171,620 according to [16]).

3. The benefit to cost ratio is fairly insensitive to injury rates. 


\section{Direct property losses}

The average loss per unsprinklered house fire was obtained from the 1995 data base of the New South Wales Fire Brigade (corrected for inflation): A $\$ 24,000$. The figure for sprinklered fire was obtained by applying a reduction of $84 \%$ said to have been observed in Scottsdale USA ([18]): A $\$ 3,900$.

\section{Insurance savings}

Insurance savings have not been included in this study because the benefit to cost ratio is a societal indicator. In accordance with the Kaldor-Hicks Compensation principle mentioned above, it is unaffected by transfer payments from one group in society to another group, which is what insurance is.

\section{REFERENCES}

[1] Beever, P. and Britton, M. (1999) Research into Cost-Effective Fire Safety Measures for Residential Buildings. Building Control Commission, Melbourne, Victoria, Australia.

[2] Nathwani, J.S., Lind, N.C., and Pandey, M.D. (1997) Affordable Safety by Choice. Institute for Risk Research, University of Waterloo, Canada.

[3] Pandey, M.D. and Nathwani, J.S. (2004) Life quality index for the estimation of societal $\begin{array}{lllll}\text { willingness-to-pay for } \quad \text { safety. Structural } & \text { Safety } 26,181-199\end{array}$ doi.org/10.1016/j.strusafe.2003.05.001

[4] Ramachandran, G. (1995) Monetary value of human life. Chapter 8, Section 5 of SFPE Handbook of Fire Protection Engineering, 2nd edn, Quincy, MA.

[5] Ramachandran, G. and Hall, J.R.Jr.(2002) Measuring Fire Consequences in Economic Terms. Chapter 6, Section 5 of SFPE Handbook of Fire Protection Engineering, 3rd edn, Quincy, MA.

[6] Thaler, R. and Rosen, S. (1976) The value of life saving. In Household Production and Consumption, N. Terleckyj (ed). NBER Press, Columbia University.

[7] Butry,D.T., Brown,M.H. and Fuller, S.K. (2007) Benefit-Cost Analysis of Residential Fire sprinkler Systems, NISTR 7451.

[8] Australian Bureau of Statistics (2004) Life Tables Australia 2001-2003, Catalogue No. 3302.0.55.00

[9] OECD (2005) Society at a Glance: OECD Social Indicators, OECD.

[10] Lind, N.C., Nathwani, J.S. and Siddall, E. (1991) Management of Risk in the Public Interest, Canadian journal of civil Engineering, 18, 446-453.

[11] Voortman, H.G., van Gelder, P.H.A.J.M., Vrijling, J.K. and Pandey, M.D. (2003) Definition of acceptable risk in flood-prone areas, European Safety and Reliability Conference 2003, Maastricht, The Netherlands

[12] Rackwitz, R. (2002) Optimization and risk acceptability based on the Life Quality Index. Structural safety 24, 297-331 doi.org/10.1016/S0167-4730(02)00029-2

[13] Pandey, M.D. and Nathwani, J.S. (2003). Canada Wide Standard for Particulate Matter and Ozone: Cost-Benefit Analysis using a Life-Quality Index. Int. J. Risk Analysis, 23(1), 55-67 $\underline{\text { doi:10.1111/1539-6924.00289 }}$

[14] Rabl, A., Nathwani, J., Pandey, M.D. and Hurley, F. (2003) Tools and Strategies for Improving Policy Responses to the Risk of Air Pollution, Int. Conf. Strategies for Clean Air and Health. 5-7 November, Rome, Itlay.

[15] Pandey, M.D. and Nathwani, J.S. (2003) A Conceptual Approach to the Estimation of Societal Willingness-to-Pay for Nuclear Safety Programs. Int. J. Nuclear Engineering and Design, 224(1), 65-77 doi:10.1016/S0029-5493(03)00062-1. 
[16] Viscusi, W.K. and Aldy, J.E. (2003) The value of a Statistical Life: A Critical Review of Market Estimates Throughout the World”, Journal of risk and Uncertainty, 27,(1), 5-76 doi:10.1023/A:1025598106257

[17] Viscusi, W.K. (1992) Fatal Trade Offs: Public and Private Responsibilities for Risk, Oxford University Press, NY, 6480, Gaithersburg, MD, 2000, 12 p.

[18] Siarnicki, R.J. (2001) Residential Sprinklers: One community's experience twelve years after mandatory implementation. Executive Leadership. By: Ronald Jon Siarnicki. Fire Chief. An applied research project submitted to the National Fire Academy as part of the Executive Fire Officer Program 